\title{
Prophylactic Strategy for Peritoneal Recurrence after Curative Operation in Pancreatic Cancer
}

\author{
Kenichiro Yamamoto ${ }^{1 *}$, Shinya Shimada ${ }^{1}$, Masafumi Kuramoto ${ }^{1}$, Satoshi Ikeshima1, Toshiro Masuda ${ }^{1}$, Kenichi Nakamura1, Shinichi \\ Yoshimatsu², Masayuki Urata² and Hideo Baba ${ }^{3}$ \\ ${ }^{1}$ Department of Surgery, Kumamoto Social Insurance General Hospital, Yatsushiro, Kumamoto, Japan \\ ${ }^{2}$ Department of Gastroenterology and Hepatology, Kumamoto Social Insurance General Hospital, Yatsushiro, Kumamoto, Japan \\ ${ }^{3}$ Department of Gastroenterological Surgery, Kumamoto University Graduate School of Medical Sciences, Kumamoto, Japan
}

\begin{abstract}
Even though curative surgery has been performed for patients with pancreatic cancer without peritoneal free cancer cells at laparotomy, many patients die of peritoneal recurrence. The reason for this fact is postulated that the surgical procedure itself could cause spread of cancer cells into peritoneal cavity. To identify the free cancer cells spilled in the peritoneal cavity during the operation, we have established real-time quantitative reverse transcription Polymerase Chain Reaction (RT-PCR) system. Moreover, we have devised Extensive Intraoperative Peritoneal Lavage (EIPL) therapy as a very simple and non-aggressive prophylactic treatment for peritoneal dissemination of gastric cancer patients with peritoneal free cancer cells. In this paper, we review the validity of EIPL therapy navigated by real-time quantitative RT-PCR detecting free cancer cells in the peritoneal cavity during operation, and the effect of this therapy on the survival after curative operations in patients with pancreatic cancer.
\end{abstract}

Keywords: Pancreatic cancer; Peritoneal free cancer cells; EIPL therapy; RT-PCR

\section{Introduction}

Pancreatic cancer is one of the leading causes of cancer-related death in industrialized countries [1], and is well known as a miserable disease with the overall 5 -year survival rate ranging from $7 \%$ to $25 \%$ after potentially curative surgical operation [2-6]. One of the major features of pancreatic cancer is its early peritoneal dissemination as well as liver metastasis after curative surgical treatment [7-10]. Peritoneal recurrence was found in more than half of the patients, which determines the high mortality rate $[8,9]$. To improve longterm survival, multidisciplinary approaches combined with surgery whenever possible have been adopted to try to eradicate the recurrent patterns, but these measures do not seem to improve survival any more than that by standard resection [11-14].

Although it is thought that the minimal cancer cells that already existed at the site of recurrence (Micrometastasis) at the time of surgery may be a mechanism of recurrence [15-17]. The surgical operation itself might have caused the peritoneal dissemination of these cancer cells. In fact, it has been proven that surgical procedures for gastrointestinal cancers disseminate cancer cells into the systemic circulation and or intra-peritoneal space [18-20]. If possible, this type of cancer dissemination should be eradicated at the time of the surgical operation.

We have established EIPL (Extensive Intra-operative Peritoneal Lavage) therapy as a useful technique that eradicates the intra-peritoneal free cancer cells in patients with gastric cancer to prevent peritoneal metastasis before implantation of the peritoneal free cancer cells $[20,21]$. The peritoneal cavity was extensively washed and completely aspirated using 11 of physiological saline 10 times based on the limiting dilution method' after the potentially curative operation. EIPL therapy is quite a powerful method for reducing the number of peritoneal free cancer cells to potentially zero. Our recent study has clearly revealed that combined with intraperitoneal chemotherapy, EIPL therapy significantly improved the survival of the gastric cancer patients with peritoneal free cancer cells without peritoneal disseminations after potentially curative operations [21,22]. Recently, we employed EIPL therapy for the patients with pancreatic cancer after a curative operation and obtained favorable results [23].
In this review article, we focus on the usefulness of evaluating the status of abdominal free cancer cells by using the ultra-rapid quantitative Reverse Transcription Polymerase Chain Reaction (RTPCR) system and the ability of EIPL therapy as a prophylactic strategy for peritoneal recurrence in patients with pancreatic cancer after curative operation.

\section{Detection of intraperitoneal free cancer cells by real-time quantitative RT-PCR}

Cytological analysis has been the gold standard for detecting cancer cells in the peritoneal lavage during operation, however, it has generally been said to lack of sensitivity. In recent years, molecular approaches using the PCR technique have been applied to various clinical fields and have become one of the useful diagnostic tools.

RT-PCR has been developed for screening a small amount of tumor cells in circulating blood, bone marrow, lymph nodes, and peritoneal lavege fluid [24-34]. Its sensitivity is much higher than that of conventional and immunohistochemical cytological examinations [33]. So the RT-PCR technique is suitable for detecting minute quantities of peritoneal free cancer cells. However, RT-PCR has its own drawbacks, such as the following: (a) it has time-consuming gene amplification and subsequent data analysis; and (b) results of RT-PCR involve, even in low frequency, false-positive results exist by DNA contamination or pseudogenes [35].

*Corresponding author: Kenichiro Yamamoto, Department of Surgery, Kumamoto Social Insurance General Hospital, 10-10 Tohricho, Yatsushiro, Kumamoto 866-8660, Japan, Tel: +81-965-32-7111; Fax: +81-965-32-2772; E-mail: yamamoto@kumamoto-gh.jp

Received August 08, 2013; Accepted September 25, 2013; Published September 27, 2013

Citation: Yamamoto K, Shimada S, Kuramoto M, Ikeshima S,Masuda T (2013) Prophylactic Strategy for Peritoneal Recurrence after Curative Operation in Pancreatic Cancer. J Cytol Histol 4: 185. doi: 10.4172/2157-7099.1000185

Copyright: (c) 2013 Yamamoto K, et al. This is an open-access article distributed under the terms of the Creative Commons Attribution License, which permits unrestricted use, distribution, and reproduction in any medium, provided the original author and source are credited. 
Therefore, we established 'real-time quantitative RT-PCR system', which is a combined system of an ultra-rapid RT-PCR using a fully automated mRNA extractor and a real-time one-step RT-PCR system with hybridization probe format for detection of peritoneal free cancer cells. This new method enabled us to obtain the results of RT-PCR in a short time after sampling. Furthermore, we carried out multiple markers RT-PCR assay for a combination of CEA and CK20 to eliminate falsepositive results and to improve specificity.

Peritoneal lavage samples from 58 patients with non-serosainvasive gastric cancer were obtained at laparotomy and immediately after lymph node dissection, and CEA- and CK20-specific RT-PCRs were performed using the real-time quantitative RT-PCR system to identify the free cancer cells in the samples [20]. This method enabled us to complete the detection of cancer cells within approximately 70 min. In the samples of lavage at laparotomy, CEA mRNA and CK20 mRNA were not detected in patients without serosal invasion, but in the peritoneal lavage samples after lymph node dissection, both the CEA and CK20 mRNA products were detected in 13 of 63 patients (20.6\%; Figure 1) [20]. They were not observed in mucosal tumors, but were identified in three (14.3\%), four (26.7\%), and six $(46.2 \%)$ patients with submucosal, muscularis proplia, and subserosal tumors, respectively. These results suggested that lymph node dissection itself opened lymphatic channels and spread viable cancer cells into the peritoneal cavity, and this was the one of the mechanisms of peritoneal metastasis from non-serosa-invasive cancer.

\section{Extensive Intraoperative Peritoneal Lavage (EIPL) therapy}

We have proposed EIPL for reducing the number of intraperitoneal free cancer cells as a useful intraoperative technique [21]. Briefly, the peritoneal cavity is extensively stirred and washed after the potentially curative operation, which is followed by the complete aspiration of the fluid. This procedure is done 10 times using $1 \mathrm{~L}$ of physiological saline. Ten washes of a 1:10 dilution result in just 1 cancerous cell from $10^{10}$ cells in the abdominal cavity. Furthermore, sufficient stirring and washing of the abdominal cavity would remove the cancer cells which merely adhere to the peritoneum.

We performed EIPL to the five cases of serosa-invasive gastric cancer with $\mathrm{CY}+/ \mathrm{P}-$, and its efficacy was evaluated by the ultra-rapid quantitative RT-PCR protocol. Sequential washing of intraperitoneal free cancer cells of $3.8 \times 10^{5} \pm 1.4 \times 10^{5} / 100 \mathrm{ml}$ of lavage decreased the

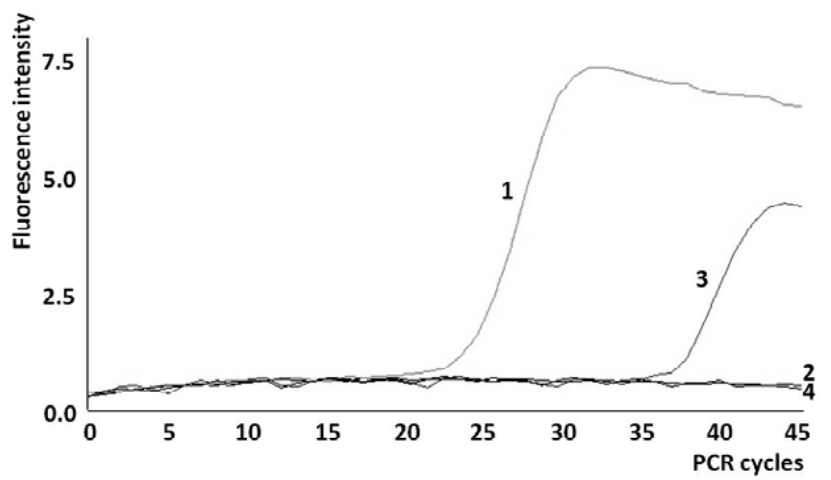

Figure 1: Representative results of ultra-rapid RT-PCR by LightCycler in a patient with SM tumor of well-differentiated adenocarcinoma with lymph node metastasis and lymphatic invasion. Curve 1, WiDr colon cancer cells as a positive control; curve 2, i.p. lavage sample at laparotomy; curve 3, i.p. lavage sample immediately after lymph node dissection; curve 4 , no template as a negative control.

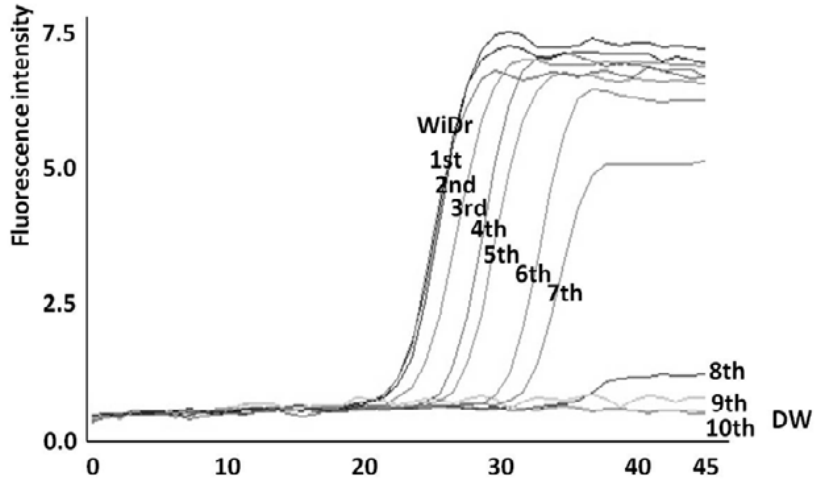

Figure 2: Representative results of ultra-rapid quantitative RT-PCR of the serial extensive lavages by LightCycler. Curves and Lanes 1st-10th were $100-\mathrm{ml}$ samples from the first to the tenth wash, each using 1 liter of saline. WiDr was a positive control containing 105 cells in $100 \mathrm{ml}$ of saline, and DW contained no template. The free cancer cells in the lavage fluids were serially diluted by 8 liters of saline and disappeared in washing fluids after the eighth wash.

number to $2.8 \pm 1.5$ cells by 6 to 8 washes. Free cancer cells were not detected in the fluid after that (Figure 2) [20]. On the other hand, $2.8 \times$ $10^{4} \pm 4.5 \times 10^{4}$ of intraperitoneal free cancer cells still remained in $100 \mathrm{ml}$ of the lavage when not treated with EIPL.

\section{Application of EIPL Therapy to Pancreatic Cancer}

\section{Analysis of free cancer cells during the operation}

As a pilot study, we undertook real-time quantitative RT-PCR of the peritoneal lavage fluid from 8 patients who underwent pancreatectomy (6 patients of pancreatic cancer, 1 patient of pancreatic cancer with peritoneal dissemination, 1 patient of chronic pancreatitis) [23]. Peritoneal lavage was performed three times during the operation: at the time of laparotomy, immediately after lymph node dissection and after pancreatectomy. The results were that both CEA mRNA and CK20 mRNA products were observed in 2 (33.3\%) and 4 (66.7\%) patients with pancreatic cancer after lymph node dissection and removal of the tumor, respectively (Table 1) [23]. These data suggest that the operation itself could cause spreading of cancer cells to peritoneal cavity, which then would lead to peritoneal recurrence after curative surgery for pancreatic cancer as well as gastric cancer like we previously demonstrated.

\section{EIPL therapy in pancreatic cancer}

We adopted EIPL therapy to pancreatectomy for the patients with pancreatic cancer to confirm the impact of EIPL therapy in preventing peritoneal recurrence after a curative surgical operation [23]. We designed a cohort study for the pancreatic cancer patients. This study was based on 39 consecutive patients with invasive ductal adenocarcinoma of the pancreas who underwent curative surgical treatment. The patients were divided into two groups: the non-EIPL group, patients without EIPL therapy $(\mathrm{n}=24)$; and the EIPL group, patients with EIPL therapy $(n=15)$. All patients were followed up at the outpatient clinic every 2 to 3 months, and computed tomography was ordered to check any recurrences every 4 to 6 months. Any patients did not receive adjuvant chemotherapy.

Clinicopathological findings including the mean age, sex, location of tumor, pathological tumor stage, histological type and surgical treatment did not differ between the two groups, but peritoneal recurrence was significantly reduced in the EIPL group, compared 
Citation: Yamamoto K, Shimada S, Kuramoto M, Ikeshima S,Masuda T (2013) Prophylactic Strategy for Peritoneal Recurrence after Curative Operation in Pancreatic Cancer. J Cytol Histol 4: 185. doi: 10.4172/2157-7099.1000185

Page 3 of 5

\begin{tabular}{|c|c|c|c|c|c|c|c|c|c|}
\hline \multirow{2}{*}{ Patient No. } & \multicolumn{5}{|c|}{ Real-time quantitative RT-PCR (cell/100ml) } & \multirow[t]{2}{*}{$\mathrm{T}^{*}$} & \multirow[t]{2}{*}{$\mathrm{N}^{*}$} & \multirow{2}{*}{$\begin{array}{l}\text { Recurrent } \\
\text { pattern }\end{array}$} & \multirow{2}{*}{$\begin{array}{l}\text { Disease-free } \\
\text { Period (months) }\end{array}$} \\
\hline & \multicolumn{2}{|l|}{ Laparotomy } & After LN resection & After pancreatectomy & After EIPL & & & & \\
\hline \multicolumn{10}{|c|}{ Pancreatic cancer } \\
\hline 1 & \multicolumn{2}{|c|}{ negative } & negative & negative & NA & 3 & 0 & none & alive \\
\hline 2 & \multicolumn{2}{|c|}{ negative } & negative & 135 & negative & 2 & 1 & liver & 6 \\
\hline 3 & \multicolumn{2}{|l|}{ negative } & negative & 285 & negative & 3 & 0 & none & alive \\
\hline 4 & \multicolumn{2}{|c|}{ negative } & 950 & 2313 & negative & 3 & 1 & liver & 4 \\
\hline 5 & \multicolumn{2}{|c|}{ negative } & negative & negative & NA & 2 & 0 & liver & 4 \\
\hline 6 & \multicolumn{2}{|c|}{ negative } & 851 & 783 & negative & 4 & 1 & lung & 13 \\
\hline \multicolumn{10}{|c|}{ Pancreatic cancer with peritoneal dissemination } \\
\hline & 1 & 5210 & ND & ND & NA & 4 & 1 & peritoneal & 0 \\
\hline \multicolumn{10}{|l|}{ Pancreatitis } \\
\hline \multicolumn{2}{|r|}{1} & negative & negative & negative & NA & & & & \\
\hline
\end{tabular}

EIPL: extensive intraoperative peritoneal lavage therapy, LN: lymph node, *UICC classification, NA: EIPL therapy was not applicable, ND: not done.

Table 1: Real-time quantitative RT-PCR of peritoneal lavage fluid in serial surgical procedures.

\begin{tabular}{|c|c|c|c|c|c|}
\hline \multirow{2}{*}{ Recurrent pattern } & \multirow{2}{*}{$\begin{array}{c}\text { EIPL } \\
(n=15)\end{array}$} & & \multirow{2}{*}{$\begin{array}{c}\text { Non-EIPL } \\
(n=24)\end{array}$} & & \multirow{2}{*}{$P$ value } \\
\hline & & & & & \\
\hline Peritoneal & 1 & $(6.7)$ & 11 & $(45.8)$ & 0.013 \\
\hline Hepatic & 6 & $(40.0)$ & 12 & $(50.0)$ & 0.742 \\
\hline Lymph node & 4 & $(26.7)$ & 5 & $(20.8)$ & 0.711 \\
\hline Local & 2 & $(13.3)$ & 7 & $(29.2)$ & 0.437 \\
\hline Extra-abdominal & 2 & $(13.3)$ & 5 & $(20.8)$ & 0.685 \\
\hline Total & 9 & $(60.0)$ & 20 & $(83.3)$ & 0.141 \\
\hline
\end{tabular}

EIPL: patients with extensive intraoperative peritoneal lavage therapy, ( ): \%.

Table 2: Comparison of recurrent patterns between the groups with and without EIPL therapy.

\begin{tabular}{|c|c|c|c|}
\hline Variable & Risk ratio & P value & $0.0 \mathrm{Cl}$ \\
\hline $\mathrm{N}$ & 13.072 & 0.040 \\
\hline (positive vs negative) & & $0.124-152.075$ \\
\hline EIPL & 0.084 & $0.007-0.936$ \\
\hline (with vs without) & & \\
\hline
\end{tabular}

$\mathrm{N}$ : lymph node metastasis, EIPL: extensive intraoperative peritoneal lavage therapy.

Table 3: Multivariate analysis of the independent risk factors for peritoneal recurrence.

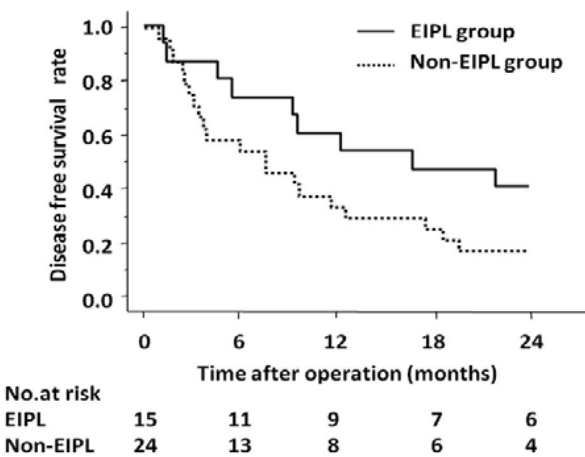

Figure 3: Kaplan-Meier disease free survival curves for the EIPL (extensive intraoperative peritoneal lavage) and non-EIPL groups $($ log-rank test, $P=0.097)$. Solid line: patients with EIPL therapy, broken line: patients without EIPL therapy.

with the non-EIPL group (Table 2) [23]. Univariate logistic regession analysis showed that peritoneal recurrence had significant correlation with lymph node metastasis and EIPL therapy, and multivariate analysis revealed that lymph node metastasis and EIPL therapy were independent factors related to peritoneal recurrence. EIPL therapy was an independent negative risk factor for formation of peritoneal recurrence after curative operation, whereas lymph node metastasis was a positive one (Table 3) [23].

Based on these findings, we analyzed whether EIPL therapy improved cancer-free survival after curative operation. The 2-year cancer-free survival rates of the non-EIPL and EIPL group were $16.7 \%$ and $40 \%$, respectively (Figure 3) [23]. The cancer specific 2-year 
Citation: Yamamoto K, Shimada S, Kuramoto M, Ikeshima S,Masuda T (2013) Prophylactic Strategy for Peritoneal Recurrence after Curative Operation in Pancreatic Cancer. J Cytol Histol 4: 185. doi: 10.4172/2157-7099.1000185

survival curve of the EIPL group tended to be improved compared with the non-EIPL group, and was nearly of statistical significance.

\section{Validity of EIPL therapy in the operation of pancreatic cancer}

These our results strongly indicate that the serial surgical procedures of pancreatectomy are major factors in the spread of variable free cancer cells into the peritoneal cavity leading to the formation of peritoneal recurrence after curative operation. We have previously proposed that EIPL therapy is quite a formidable method for reducing the number of cells to potentially zero. Therefore, we applied this therapy to patients with pancreatic cancer in which free cancer cells might spill through due to the surgical procedures. In fact, large numbers of cancer cells disseminated into the peritoneal cavity during operation, as already described. Statistical analysis demonstrated that EIPL therapy was an independent factor in preventing the formation of peritoneal recurrence. Furthermore, the 2-year cancer-free survival of the EIPL group was substantially improved compared with the non-EIPL group. In our pilot study, no-touch isolation technique followed by EIPL therapy decreased the total recurrence after curative operation for pancreatic cancer [36]. Thus, to improve long-term survival in such an aggressive disease as pancreatic cancer, a combined treatment of EIPL with no-touch isolation surgery followed by effective chemotherapy may be worth trying to eradicate recurrence after curative operation.

\section{Conclusion}

EIPL therapy navigated by real-time quantitative RT-PCR detecting free cancer cells spilled in the peritoneal cavity during operation is a new strategy preventing peritoneal recurrence, especially in patients with pancreatic or gastric cancer, in which peritoneal dissemination is common after curative operation. Frequent washing and complete aspiration may not be an appealing activity at the end of a time consuming operation, but this procedure is quite a powerful method for reducing the number of cells to potentially zero and, furthermore, it can be performed anywhere and at anytime. The use of EIPL may be applied to all patients with pancreatic cancer after curative operation as well as to patients with cytological peritoneal free cancer cells without overt peritoneal dissemination.

\section{References}

1. Niederhuber JE, Brennan MF, Menck HR (1995) The National Cancer Data Base report on pancreatic cancer. Cancer 76: 1671-1677.

2. Trede M, Schwall G, Saeger HD (1990) Survival after pancreatoduodenectomy. 118 consecutive resections without an operative mortality. Ann Surg 211: 447458.

3. Warshaw AL, Fernandez-del Castillo C (1992) Pancreatic carcinoma. N Engl J Med 326: 455-465.

4. Geer RJ, Brennan MF (1993) Prognostic indicators for survival after resection of pancreatic adenocarcinoma. Am J Surg 165: 68-72.

5. Nitecki SS, Sarr MG, Colby TV, van Heerden JA (1995) Long-term survival after resection for ductal adenocarcinoma of the pancreas. Is it really improving? Ann Surg 221: 59-66.

6. Li D, Xie K, Wolff R, Abbruzzese JL (2004) Pancreatic cancer. Lancet 363: 1049-1057.

7. Griffin JF, Smalley SR, Jewell W, Paradelo JC, Reymond RD, et al. (1990) Patterns of failure after curative resection of pancreatic carcinoma. Cancer 66: 56-61.

8. del Castillo CF, Warshaw L (1993) Peritoneal metastases in pancreatic carcinoma. Hepatogastroenterology 40: 430-432.

9. Kayahara M, Nagakawa T, Ueno K, Ohta T, Takeda T, et al. (1993) An evaluation of radical resection for pancreatic cancer based on the mode of recurrence as determined by autopsy and diagnostic imaging. Cancer 72: 2118-2123.
10. Sperti C, Pasquali C, Piccoli A, Pedrazzoli S (1997) Recurrence after resection for ductal adenocarcinoma of the pancreas. World J Surg 21: 195-200.

11. Kremer B, Vogel I, Lüttges J, Klöppel G, Henne-Bruns D (1999) Surgical possibilities for pancreatic cancer: extended resection. Ann Oncol 10 Suppl 4 : 252-256.

12. Klinkenbijl JH, Jeekel J, Sahmoud T, van Pel R, Couvreur ML, et al. (1999) Adjuvant radiotherapy and 5 -fluorouracil after curative resection of cancer of the pancreas and periampullary region: phase III trial of the EORTC gastrointestinal tract cancer cooperative group. Ann Surg 230: 776-782.

13. Henne-Bruns D, Vogel I, Lüttges J, Klöppel G, Kremer B (2000) Surgery for ductal adenocarcinoma of the pancreatic head: staging, complications, and survival after regional versus extended lymphadenectomy. World J Surg 24: $595-601$.

14. Wagner M, Redaelli C, Lietz M, Seiler CA, Friess H, et al. (2004) Curative resection is the single most important factor determining outcome in patients with pancreatic adenocarcinoma. Br J Surg 91: 586-594.

15. Thorban S, Roder JD, Pantel K, Siewert JR (1996) Immunocytochemical detection of isolated epithelial tumor cells in bone marrow of patients with pancreatic carcinoma. Am J Surg 172: 297-298.

16. Tamagawa E, Ueda M, Takahashi S, Sugano K, Uematsu S, et al. (1997) Pancreatic lymph nodal and plexus micrometastases detected by enriched polymerase chain reaction and nonradioisotopic single-strand conformation polymorphism analysis: a new predictive factor for recurrent pancreatic carcinoma. Clin Cancer Res 3: 2143-2149.

17. Demeure MJ, Doffek KM, Komorowski RA, Redlich PN, Zhu YR, et al. (1998) Molecular metastases in stage I pancreatic cancer: improved survival with adjuvant chemoradiation. Surgery 124: 663-669.

18. Sales JP, Wind P, Douard R, Cugnenc PH, Loric S (1999) Blood dissemination of colonic epithelial cells during no-touch surgery for rectosigmoid cancer. Lancet 354: 392

19. Sadahiro S, Suzuki T, Tokunaga N, Yurimoto S, Yasuda S, et al. (2001) Detection of tumor cells in the portal and peripheral blood of patients with colorectal carcinoma using competitive reverse transcriptase-polymerase chain reaction. Cancer 92: 1251-1258.

20. Marutsuka T, Shimada S, Shiomori K, Hayashi N, Yagi Y, et al. (2003) Mechanisms of peritoneal metastasis after operation for non-serosa-invasive gastric carcinoma: an ultrarapid detection system for intraperitoneal free cancer cells and a prophylactic strategy for peritoneal metastasis. Clin Cancer Res 9 : 678-685.

21. Shimada S, Tanaka E, Marutsuka T, Honmyo U, Tokunaga H, et al. (2002) Extensive intraoperative peritoneal lavage and chemotherapy for gastric cancer patients with peritoneal free cancer cells. Gastric Cancer 5: 168-172.

22. Kuramoto M, Shimada S, Ikeshima S, Matsuo A, Yagi Y, et al. (2009) Extensive intraoperative peritoneal lavage as a standard prophylactic strategy for peritoneal recurrence in patients with gastric carcinoma. Ann Surg 250:242246.

23. Yamamoto K, Shimada S, Hirota M, Yagi Y, Matsuda M, et al. (2005) EIPL (extensive intraoperative peritoneal lavage) therapy significantly reduces peritoneal recurrence after pancreatectomy in patients with pancreatic cancer. Int J Oncol 27: 1321-1328.

24. Burchill SA, Bradbury MF, Pittman K, Southgate J, Smith B, et al. (1995) Detection of epithelial cells in peripheral blood by reverse transcriptasepolymerase chain reaction. $\mathrm{Br} \mathrm{J}$ Cancer 71: 278-281.

25. Vogel I, Kalthoff $H$ (2001) Disseminated tumor cells. Their detectionand significance for prognosis of gastrointestinal and pancreatic carcinomas. Virchows Arch 439: 109-117.

26. Johnson PW, Burchill SA, Selby PJ (1995) The molecular detection of circulating tumor cells. Br J Cancer 72: 268-276.

27. Raj G V, Moreno JG, Gomella LG (1998) Utilization of polymerase chain reaction technology in detection of solid tumors. Cancer 82: 1419-1442.

28. Mori M, Mimori K, Ueo H, Karimine N, Banard GF, et al. (1996) Molecular detection of circulating solid carcinoma cells in the peripheral blood: the concept of early systemic disease. Int. J. Cancer 68: 739-743.

29. Gerhard M, Juhl H, Kalthoff H, Schreiber H W, Wagener C, et al. (1994) Specific detection of carcinoembryonic antigenexpressing tumor cells in bone marrow aspirates by polymerase chain reaction. J. Clin. Oncol 12: 725-729. 
Citation: Yamamoto K, Shimada S, Kuramoto M, Ikeshima S,Masuda T (2013) Prophylactic Strategy for Peritoneal Recurrence after Curative Operation in Pancreatic Cancer. J Cytol Histol 4: 185. doi: 10.4172/2157-7099.1000185

Page 5 of 5

30. Mori M, Mimori K, Inoue H, Barnard G F, Tsuji K, et al. (1995) Detection of cancer micrometastases in lymph nodes by reverse transcriptase-polymerase chain reaction. Cancer Res 55: 3417-3420.

31. Soong R, Bayser K, Basten O (2001) Quantitative reverse transcriptionpolymerase chain reaction detection of cytokeratin 20 in noncolorectal lymph nodes. Clin. Cancer Res 7: 3423-3429.

32. Nakanishi H, Kodera Y, and Torii A, Hirai T, Yamamura Y et al. (1997) Detection of carcinoembryonic antigen-expressing free tumor cells in peritoneal washes from patients with gastric carcinoma by polymerase chain reaction. Jpn J. Cancer Res 88: 687-692.

33. Kodera Y, Nakanishi H, Yamamura Y, Shimizu Y, Torii A, et al. (1998) Prognostic value and clinical implications of disseminated cancer cells in the peritoneal cavity detected by reverse transcriptase-polymerase chain reaction and cytology. Int. J. Cancer 79: 429-433.
34. Nakanishi H, Kodera Y, Yamamura Y, Ito S, Kato T, et al. (2000) Rapid quantitative detection of carcinoembryonic antigen-expressing free tumor cells in the peritoneal cavity of gastric cancer patients with real-time RT-PCR on the LightCycler. Int J Cancer Predict Oncol 89: 411-417.

35. Broll R, Weschta M, Windhoevel U, Berndt S, Schwandner O, et al. (2001) Prognostic significance of free gastrointestinal tumor cells in peritoneal lavage detected by immunocytochemistry and polymerase chain reaction. Langenbecks Arch. Surg 386: 285-292.

36. Hirota M, Shimada S, Yamamoto K, Tanaka E, Sugita H, et al. (2005) Pancreatectomy using the no-touch isolation technique followed by extensive intraoperative peritoneal lavage to prevent cancer cell dissemination: a pilot study. JOP 6: 143-151. 